\title{
Multiphase Vortex Flow Patterns in Slab Caster Mold: Experimental Study
}

\author{
Peri Subrahmanya SRINIVAS, ${ }^{1,3) *}$ Anugrah $\mathrm{SINGH}^{2}{ }^{2)}$ Jose Martin KORATH ${ }^{1)}$ and Amiya Kumar JANA ${ }^{3)}$ \\ 1) Automation Division, Tata Steel, Jamshedpur, 831001 India. \\ 2) Department of Metallurgical and Material Science, MNIT Jaipur, Jaipur, 302017 India. \\ 3) Chemical Engineering Department, IIT Kharagpur, Kharagpur, 72130 India.
}

(Received on February 1, 2017; accepted on May 2, 2017)

\begin{abstract}
Vortexing in continuous slab casting mould is a complex inter-related phenomenon of multiphase fluid flow which can entrain mould powder and deteriorate the end product quality. In this contribution, a 0.4-scale water model has been employed to investigate the interactive effects of the operational parameters including, partial clogging of SEN ports, water flow rates, submerged entry nozzle (SEN) immersion depth and air flow rates. Operating conditions like higher values of air flow rates and deeper submergence depth of the SEN are found to reduce vortex frequencies. At higher air flow rates, bubbles emerging from the SEN port would have higher diameter and hence higher terminal velocity. Also, at higher air flow rates, volume fraction in the vicinity of the SEN is high. Raising larger bubbles with high volume fraction and high terminal velocities, during their interaction with the liquid flow streams approaching the meniscus, would reduce the horizontal velocity components to very low values. As a consequence, the shearing effect between the liquid streams fast approaching the SEN would be decreased, leading to reduction in vortex frequencies. The bubble rising pattern along with the upper circulation loop is found to vary with the SEN submergence depth. At deeper submergence depth, larger fraction of gas bubbles traversing along the upper recirculation loop would reach to a point which is very close to the SEN and escape into atmosphere from there. On contrary, this point of contact between gas bubbles and the meniscus is comparatively away from the SEN at shallow submergence depths. As known, vortices are formed in the vicinity of the SEN where the shearing effect is the maximum. In case of deeper submergence depth, the ascending gas bubbles interact with the swirling and reduce the shearing effect and hence the vortex formation. These findings of the current study are important in controlling the mould powder entrainment through vortexing.
\end{abstract}

KEY WORDS: continuous casting; multiphase flow; vortex; slivers; water model experiment; SEN port clogging.

\section{Introduction}

Economic viability, high productivity and operational flexibility have contributed to the success of continuous casting process which has been widely accepted in steel industry. Today continuous casting is employed to solidify over $95 \%$ of steel ${ }^{1)}$ in the world. In this process, liquid steel from tundish flows through a submerged entry nozzle (SEN) into copper mould, a rectangular cavity. On the outer walls of the copper mould, there is a cooling arrangement which removes heat from liquid steel and enables steel solidification. Details of this complex phenomenon can be understood from previous works. ${ }^{2-4)}$

Fluid flow inside the submerged entry nozzle (SEN) and the mould cavity is essentially multiphase in nature owing to the intensive interaction between Argon gas bubbles, liquid metal, and liquefied mould powder. Understanding the multiphase flow structures and characteristics such as

\footnotetext{
* Corresponding author: E-mail: ps.srinivas@tatasteel.com DOI: http://dx.doi.org/10.2355/isijinternational.ISIJINT-2017-062
}

vortexing, inclusion floating, and generation of recirculation zones are of fundamental importance because they influence product quality. At the mould meniscus, vortices are generated in the vicinity of SEN. As explained by the previous researchers, ${ }^{5-8)}$ there are three possible mechanisms that can cause vortex formation. The first one is the bathtub $^{5)}$ mechanism. This is observed when fluid drains out of a container. The second one is the Karman ${ }^{6,7)}$ vortex mechanism. When fluid flows around a bluff body, wakes are observed in the leeward side. The flow separation on the leeward side also causes repeating pattern of swirling vortices. The third mechanism is the shearing ${ }^{8)}$ of the flow currents approaching each other in opposite directions as noticed in whirlpools. Among the three mechanisms, it seems the shearing effect is the predominant mechanism that causes vortex formation. In continuous caster, flow jets emerged from the SEN outports hit the narrow plate and break into two different circulatory rolls-upper and lower. The flow streams of upward moving roll, when reached the meniscus, would move towards the SEN in horizontal direction. They would pass through the narrow gap between SEN 
and mould walls and shear the streams approaching from the opposite direction. The shearing of flow streams would create vortices. The flow characteristics of the vortices are of two-fold-a) two-dimensional rotation of fluid flow in the horizontal plane and $b$ ) three-dimensional rotational downward flow towards the SEN port. Vortices can entrain the mould powder slag and transport it deeply down into the liquid pool. ${ }^{9-11)}$ This entrained flux can lead to the formation of a sliver-a defect on the surface of the final rolled product.

Vortex formation adjacent to the SEN was noticed by many previous researchers ${ }^{5,12,13)}$ with the help of water model experiments. $\mathrm{He}^{12)}$ has observed that the flow-bias from the outports of the SEN would cause vortices. Flow bias/asymmetry can happen due to many reasons. Nozzle clogging is one among them. Deposition of inclusions, particularly alumina already present in the steel, ${ }^{15)}$ at the out ports of the SEN would lead to nozzle clogging. Alumina affinity towards hot refractory lining of the SEN and the influence of the surface energy ${ }^{16-18)}$ are the two prime reasons for deposition. As a consequence, the nozzle ports are partially blocked. Rödl et al. ${ }^{19)}$ from their plant data analysis, have reported that sticking tendency of Alumina particles are high near the port exits than in the bore. Partial and uneven clogging of outports would result into asymmetric out flow. ${ }^{20}$ This asymmetric flow is sustained even though the jet splits into upper and lower circulatory flow after hitting the narrow plate. At the meniscus, the asymmetric flows approaching the SEN from the two narrow plates would shear with each other and produce swirling flows. Vortices, which would be originated when the rotational flow exceeds a critical value, can entrain mould powder into the liquid steel..$^{8,12,21-23)}$ Cho et al. ${ }^{23)}$ have explained the effect of nozzle clogging on flow bias and the resultant vortex formation using water model experiments. Srinivas et $a l^{24)}$ have investigated the interactive effects of process parameters like casting speed, degree of clogging and SEN submergence depth on vortex formation. However, both have dealt with single phase flow only.

Injection of argon gas through the SEN in continuous casting makes the flow multiphase. To reproduce the similar effect, many researchers have used air in the water model experimentation. In large number of air-water experimental studies, ${ }^{15,25,26)}$ the focus was mainly on air bubble aggregation, breakage and transport in the water media. A few researchers have addressed interaction between vortices and gas bubbles. Sánchez-Perez et al. ${ }^{27)}$ have observed that the injection of gas in the liquid helps destroying vortices. Liu et $a l^{28)}$ have reported the interconnected effect of casting speed and air flow rate on vortex location and sizes.

Numerical investigation is also a popular technique applied by researchers ${ }^{23,29,30)}$ to gain in-depth understanding of the vortex formation and also vortex-gas. However, this approach has some limitations. Firstly, it is very difficult to simulate the transient nature of vortex formation, movement and dissolution. Secondly, studying of vortex frequency, size and depth as a function of operating parameters- mainly SEN submergence depth and air flow rate - is very challenging through numerical simulations.

To the best of the authors' knowledge, no work has been reported addressing the interactive effects of operational parameters on vortex characteristics covering a wide operational range. Interestingly, these aspects are of great practical significance. Therefore, to gain comprehensive understanding of vortexing and mainly the interaction of raising gas bubbles and vortices, water model simulation is the appropriate choice. In this study, water model experiments have been carried out with the prime objective of analyzing and quantifying inter-related effects of clogging, casting speed, SEN submergence depth and air flow on flow asymmetry and vortex flow characteristics.

\section{Water Model Experiments}

\subsection{Apparatus}

In order to visualize vortex formation and the interaction between vortices and the ascending air bubbles, a 0.4 scale (model: actual) water model has been employed, whose schematic representation is provided in Fig. 1. This "water caster" at the R\&D division of Tata Steel, Jamshedpur, India, was made up of a transparent plastic material, Perspex. The set up has a tundish, stopper rod, SEN, mould and two rotameters to control water and air flow rates. In order to represent the actual caster closely, a porous plug is placed within the stopper rod. The length of the mould, 2 meters, is designed sufficiently long to simulate the recirculation flows and guard the flow patterns in the mould from the mouldexit disturbances. SEN has two ports with a $15^{\circ}$ downward angle having rectangular cross sections and a recess bottom. Table 1 presents the dimensions of actual and water casters.

Water flows in circuit during the experimentation. Water is pumped from the buffer tank to the tundish through a rotameter. From tundish, water flows into the mould cavity through the SEN. Through the 6 outlets, water exits the mould and reaches the buffer tank. To achieve two-phase flow, air from the compressor is fed by an air hose into the SEN through a tube inside the stopper rod. Adjusting water and air flow rates with the help of the two flow meters and the mould exit valves, steady state conditions are achieved wherein the water levels in both tundish and mould are maintained at the desired levels.

\subsection{Similarity Criterion}

Similitude analysis was performed to achieve intended flow conditions in water caster model. As the flow is multiphase, the essential dominating forces including inertial, gravitational, viscous and the gas buoyancy between liquid

Table 1. Actual and Model Dimensions.

\begin{tabular}{|c|c|c|c|}
\hline Parameter & Unit & Actual & Model \\
\hline Scale down & - & 1 & 0.4 \\
\hline Mould width & $\mathrm{mm}$ & 1500 & 600 \\
\hline Mould thickness & $\mathrm{mm}$ & 210 & 84 \\
\hline Mould length & $\mathrm{mm}$ & 900 & 2000 \\
\hline SEN bore size & $\mathrm{mm}$ & 75 & 30 (inner), 50 (outer) \\
\hline SEN port size & $\mathrm{mm}$ & $100 \times 55$ & $40 \times 22$ \\
\hline Port type (well bottom) & - & $15^{0}$ down & $15^{0}$ down \\
\hline $\begin{array}{l}\text { Diameter of the hole for } \\
\text { injection of air into stop- } \\
\text { per rod }\end{array}$ & $\mathrm{mm}$ & 5 & 1.6 \\
\hline
\end{tabular}




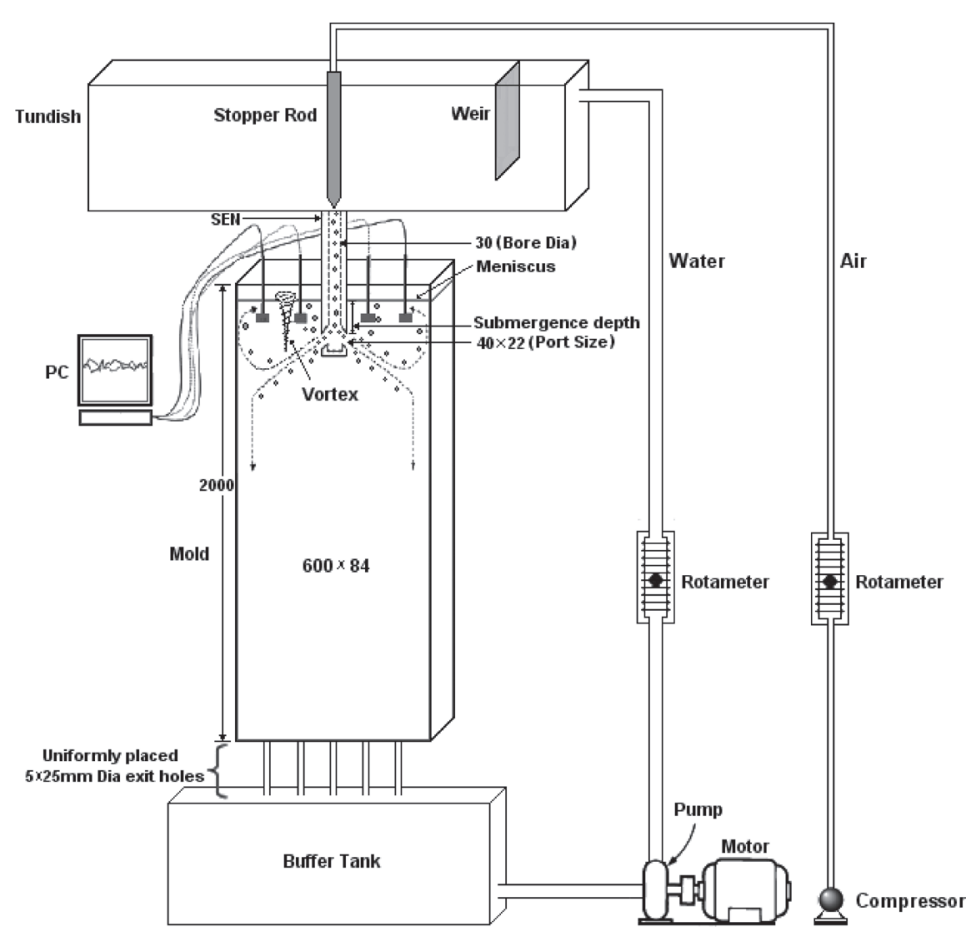

Fig. 1. Schematic illustration of water model experiment apparatus (dimensions are in $\mathrm{mm}$ ).

steel and Argon were considered to evaluate the desired water and air flow rates for the experimentation. Since the high-velocity flow conditions and a free meniscus in the actual caster necessitates for Reynolds, Froude and Weber similarities simultaneously. As long as the fully turbulent conditions are maintained in the water caster, Reynolds similitude can be relaxed. ${ }^{28)}$ The Weber number similitude is also not so applicable in the present context for two reasons. ${ }^{30)}$ First, its contribution in bubble movement and its interaction with flow/vortices is not very significant and second, there is no third phase (equivalent to slag) present in the water model. This concludes that the Froude number similitude is most relevant and by applying Froude and modified Froude similitude conditions, equal ratios of the momentum and buoyancy forces in the water model (W) and actual steel caster (A) can be achieved. Accordingly,

$$
\begin{gathered}
F r_{W}=F r_{A} \quad(\text { Froude Similarity }) \ldots . . . . . \\
F r_{W}^{m}=F r_{A}^{m} \quad(\text { modified Froude Similarity })
\end{gathered}
$$

Expanding Eq. (1), we get

$$
\frac{U_{W}^{2}}{g Y_{W}}=\frac{U_{A}^{2}}{g Y_{A}}
$$

Again, expanding Eq. (2), we get

$$
\frac{V_{W}^{2}}{g Y_{W}}\left(\frac{\rho_{\text {air }}}{\left(\rho_{\text {water }}-\rho_{\text {air }}\right)}\right)=\frac{V_{A}^{2}}{g Y_{A}}\left(\frac{\rho_{\text {Argon }}}{\left(\rho_{\text {Steel }}-\rho_{\text {Argon }}\right)}\right) \ldots
$$

Where, $U$ and $V$ are the characteristic velocities of liquid and gas, respectively, and $Y$ the characteristic length. For the current set up, the scale down factor $\lambda$ is defined as:

$$
\lambda=\frac{Y_{W}}{Y_{A}}=0.4
$$

Substituting Eq. (5) in (3), one obtains

$$
\frac{U_{W}}{U_{A}}=(0.4)^{0.5}=0.632
$$

Now, the ratios of flow rates between the water model and the actual can be obtained from:

$$
\frac{Q_{W}{ }^{\text {Liquid }}}{Q_{A}{ }^{\text {Liquid }}}=\frac{U_{W} Y_{W}^{2}}{U_{A} Y_{A}^{2}}
$$

Substituting values from Eqs. (5) and (6) in Eq. (7), we get

$$
\frac{Q_{W}{ }^{\text {Liquid }}}{Q_{A}{ }^{\text {Liquid }}}=0.101
$$

From the mass balance, casting speed is related to liquid steel mass flow rate. Ignoring the steel solidification effects on mass balance, the expression that relates casting speed and liquid steel volumetric flow is:

$$
Q_{A}^{\text {Liquid }}=U_{A} \cdot\left(w_{A}\right) \cdot\left(x_{A}\right)
$$

Where, $w$ and $x$ are mould width and thickness respectively.

Using Eqs. (8) and (9), one can obtain the expression for $Q_{W}$ as:

$$
Q_{W}^{\text {Liquid }}=0.101 * U_{A} \cdot\left(w_{A}\right) \cdot\left(x_{A}\right)
$$

Substituting all the values documented in Table 1 in Eq. (10), one gets the final expression as:

$$
Q_{W}{ }^{\text {Liquid }}=31.85 * U_{A}
$$

With this, required water flow rates $(1 / \mathrm{min})$ for the corresponding casting speeds varying from 1.2 to $1.6 \mathrm{~m} / \mathrm{min}$ are calculated and presented in the first two columns in Table 2.

While evaluating the required air flow rate for water model, Argon gas expansion in the SEN of actual caster due to hotter environment should be taken into consideration. Assuming ideal gas law holds good for Argon gas: 
$\frac{Q_{\text {Argon: } 1550^{\circ} \mathrm{C}}}{Q_{\text {Argon: } 25^{\circ} \mathrm{C}}}=\frac{\text { Volume }_{1550^{\circ} \mathrm{C}}}{\text { Volume }_{25^{\circ} \mathrm{C}}}=\frac{1823 \mathrm{~K}}{290 \mathrm{~K}}=\sim 6.22$

Relationship between gas velocity and volumetric flow rate is expressed as:

$$
\begin{gathered}
Q_{w}^{g a s}=V_{w} \frac{\pi d_{w}^{2}}{4} \\
Q_{A}^{g a s}=V_{A} \frac{\pi d_{A}^{2}}{4}
\end{gathered}
$$

Combining Eqs. (4)-(6), (12), (13) and (14), we get the relationship between Argon and air volumetric flow rates as:

$Q_{w}^{\text {gas }}=6.22 *\left(\frac{d_{w}}{d_{A}}\right)^{2} * \sqrt{\frac{Y_{W}}{Y_{A}} \frac{\rho_{\text {air }}}{\left(\rho_{\text {water }}-\rho_{\text {air }}\right)} \frac{\left(\rho_{\text {Steel }}-\rho_{\text {Argon }}\right)}{\rho_{\text {Argon }}}}$

The density values of liquid steel $\left(\rho_{\text {steel }}\right)$ and water $\left(\rho_{\text {water }}\right)$ are $7020 \mathrm{~kg} / \mathrm{m}^{3}$ and $998 \mathrm{~kg} / \mathrm{m}^{3}$. At $298 \mathrm{~K}$, the density values of air $\left(\rho_{\text {air }}\right)$ and Argon $\left(\rho_{\text {Argon }}\right)$ are $1.184 \mathrm{~kg} / \mathrm{m}^{3}$ and $1.783 \mathrm{~kg} /$ $\mathrm{m}^{3}$. Substituting all these values along with the characteristic lengths mentioned in Table 1 in Eq. (15), we get

$$
Q_{w}^{\text {gas }}=0.4026 * Q_{A}^{\text {gas }}
$$

Using the above expression, the air flow rates for the corresponding Argon flow rates are calculated and documented in the last two columns of Table 2.

\subsection{Experimentation}

Interactive effects of the four operating parameters,

Table 2. Liquid and gas flow rates for the actual and the water model casters.

\begin{tabular}{cccc}
\hline \multicolumn{2}{c}{ Liquid Flow Rates } & \multicolumn{2}{c}{ Gas Flow Rates } \\
\hline $\begin{array}{c}\text { Casting Speed } \\
(\mathrm{m} / \mathrm{min})\end{array}$ & $\begin{array}{c}\text { Water Flow Rate } \\
(1 / \mathrm{min})\end{array}$ & $\begin{array}{c}\text { Argon } \\
(1 / \mathrm{min})\end{array}$ & $\begin{array}{c}\text { Air } \\
(1 / \mathrm{min})\end{array}$ \\
\hline 1.2 & 38 & $\sim 2.5$ & 1 \\
1.4 & 45 & $\sim 5$ & 2 \\
1.6 & 50 & $\sim 7.5$ & 3 \\
\hline
\end{tabular}

namely, water flow rates, SEN submergence depths (the distance from the meniscus to the top of SEN outports), degree of clogging and most importantly, air flow rates on vortex formation, flow asymmetry are studied. Table 3 presents the details of the operating values. The selected values and the ranges of the operating parameters are in tune with the real casting process. From the table, it is clear that the total number of experiments are $(=3 \times 3 \times 3 \times 4) 108$. Figure 2 illustrates the different clogging conditions inserted in the left port only. The degree of clogging, as shown in Figs. $3(\mathrm{a}), 3(\mathrm{~b})$ and $3(\mathrm{c})$, is $0 \%, 33 \%$ and $66 \%$, respectively.

All the control points of the experimental set up-two flow meters, for water and air, mould exit valves and stopper rod position-are adjusted to achieve the steady state condition wherein the water levels in the tundish and the mould are maintained constant. An impeller velocity probe having an open-ended tube and a small propeller which rotates in accordance with water flow speed is employed to measure instantaneous flow velocities. The data polling frequency is $1 \mathrm{~Hz}^{24)}$ The recording duration is set as three minutes. This value was arrived at through a systematic approach. As understood, total number of experiments are 108 and the total number of measurements are $(=108 \times 6) 432$. Having a large recording duration would take really very long time to complete the experimentation. Therefore, smaller recording duration is a good option which can capture the flow subtleties without fail. Variations of the mean values of instantaneous measurements for three different recording durations namely, 10, 5 and 3 minutes are analyzed. It was found that the mean values derived from the three data samples and the standard deviations values are very close. Only after this verification, the recording duration is set as

Table 3. Variables and their ranges considered for the experimentation.

\begin{tabular}{lcc}
\hline \multicolumn{1}{c}{ Variable Name } & Values & Total no of Cases \\
\hline Water flow rates (1/min) & $38,45,50$ & 3 \\
SEN submergence depth $(\mathrm{mm})$ & $40,60,80$ & 3 \\
Left port (only) clogging $(\%)$ & $0,33,66$ & 3 \\
Air flow rate (1/min) & $0,1,2,3$ & 4 \\
\hline
\end{tabular}

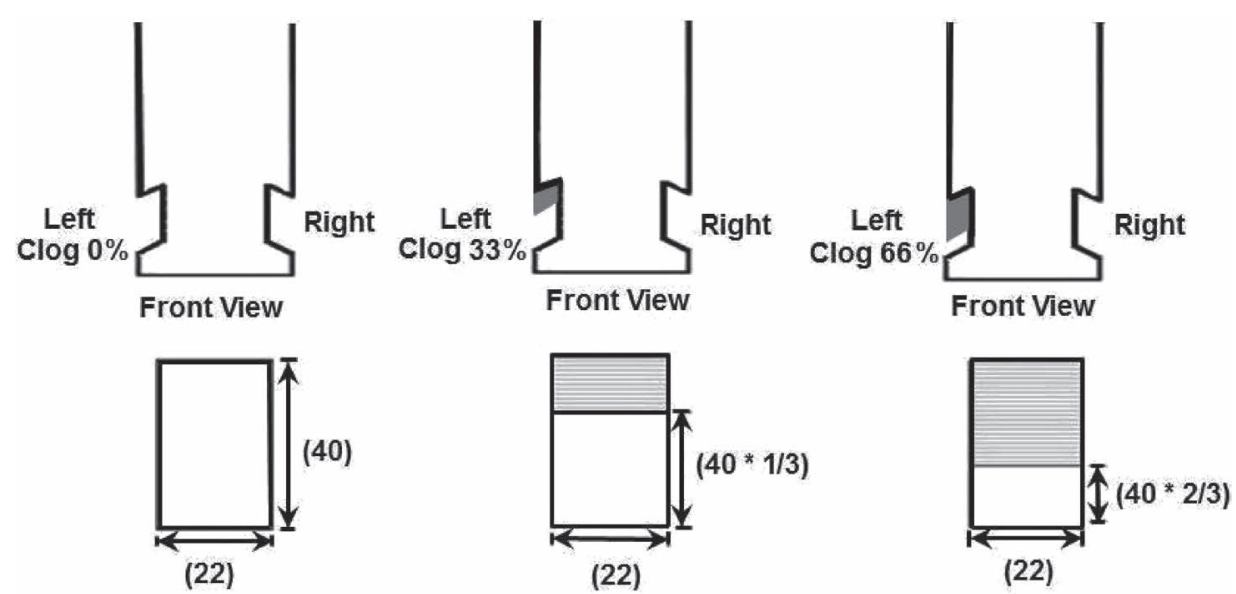

Left side view
Left side view

Fig. 2. Diagrammatic representation of nozzle clogging, (a) zero clog case, (b) $33 \%$ clog case and (c) $67 \%$ clog case (dimensions are in $\mathrm{mm}$ ). 
three minutes.

In Fig. 3, at the four points $\left(\mathrm{R}_{150}, \mathrm{R}_{250}, \mathrm{~L}_{150}, \mathrm{~L}_{250}\right) \mathrm{sub}$ meniscus velocities are measured. Letters, ' $R$ ' and ' $L$ ' indicate right and left regions of the mould. The reason for selecting the location at $250 \mathrm{~mm}$ is to get the horizontal velocities in the close vicinity of the SEN where the shearing effect prevails. Also, it is observed that the vortices are formed in this region. At the location $150 \mathrm{~mm}$, which is the midpoint between the SEN and the narrow plate, the shearing effect is supposed be very less. The two points, named as $\mathrm{P}_{\mathrm{R}}$ and $\mathrm{P}_{\mathrm{L}}$, where the port exit velocities are measured are located horizontally $250 \mathrm{~mm}$ away from narrow plate and vertically $45 \mathrm{~mm}$ further below the SEN submergence depth. For each combination of operating values, y-directed instantaneous velocities are recorded at all these six points for three minutes duration with a polling rate of one second. From these records of instantaneous values, mean flow velocities are calculated. Sesame seeds are added to the water meniscus as tracer particles to facilitate visualization of vortex formation. In each case, video recording duration is set to five minutes. The video recording duration $5 \mathrm{~min}-$ utes is also fixed based on the similar approach followed for velocity measurements.

For all experimental cases, vortices are recorded from the front view (x-direction as shown in Fig. 3). For some cases the video recording is done from the top view (z-direction) just to examine the qualitative nature of swirling flows. During the examination of the top view videos, it is noticed that in the close vicinity of the SEN, the swirling flows are observed all the time. While examining the corresponding front view videos, not all the times, the swirling flows have led to vortices which could entrain the sesame seeds deep down into the liquid pool. To distinguish the vortices of deep penetration from the rest, a minimum depth of $30 \mathrm{~mm}$, which is $10 \mathrm{~mm}$ less than the minimum SEN submergence depth, is set as one of the two criteria.

Another observation from the video analysis was that sometimes the sesame seeds were pulled deep down into the liquid pool by vertical pressure difference along the outer surface of the immersion nozzle. ${ }^{6,7)}$ In this type of entrainment, no rotational motion was noticed. Therefore, to distinguish vortex induced sesame seeds entrainment from the other mechanisms, minimum two rotations condition is introduced. In sum, the number along with the location of all vortices lasting over two rotations and having a minimum penetration depth of $30 \mathrm{~mm}$ is counted from each video

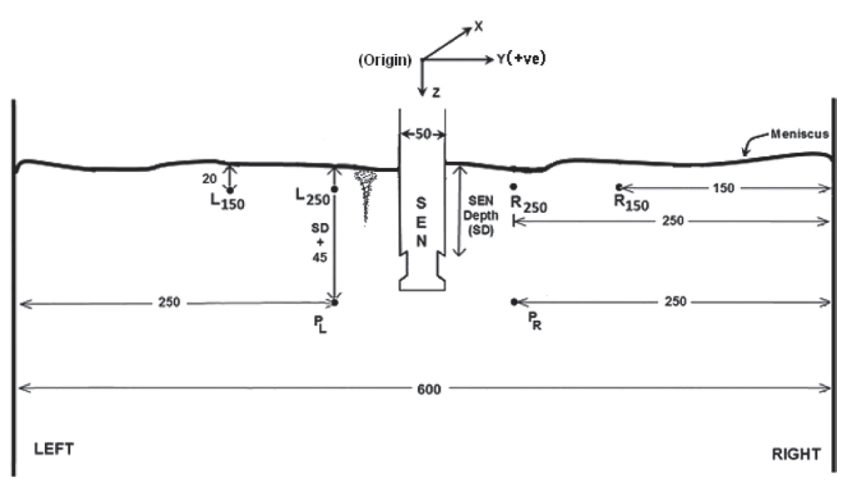

Fig. 3. Schematic representation of mould along with the points of velocity measurement. recording taken from the front view. The "vortex frequency" value is evaluated by dividing this number by total recording duration (5 minutes).

\section{Experimental Results and Discussion}

\subsection{Vortex Frequency and Flow Asymmetry}

\subsubsection{Interactive Effect of Air Flow Rate and Water Flow Rate}

Increase in air flow rates has reduced vortex formation and sustenance. Variation of vortex frequencies with air flow rates at the SEN submergence depth $60 \mathrm{~mm}$ and zero clogging has been tabulated in 2 nd to 4 th columns of Table 4. For instance, from the 4th column of Table 4, vortex frequency values at water flow rate $50 \mathrm{l} / \mathrm{min}$ are 7.2 , $3.8,1.6$ and 1.4 respectively for the corresponding air flow rates $0,1,2$, and $3 \mathrm{l} / \mathrm{min}$. Vortex frequency values at the SEN submergence depth $60 \mathrm{~mm}$ and the degree of clogging $33 \%$ and $66 \%$, are presented in 5 th to 7 th and 8 th to 10 th columns respectively in Table 4 . The reason for this inverse relationship between vortex frequency and air flow rates is explained below.

In multiphase flow, the interfacial forces including drag, pressure gradient, buoyancy, virtual mass, wall lubrication and turbulence dispersion forces ${ }^{31,32)}$ would cause momentum transfer between gas and liquid phases. In the present context, rising air bubbles would interact and exchange momentum with liquid flow streams that are approaching the meniscus and reduce their momentum. This leads to retardation of the horizontal velocity (y-directed as shown in Fig. 3) of the liquid flow streams. Also, the interaction between bubbles and the swirling flows emerged from the shearing effect would decrease the angular velocity of the rotational flows, there by suppressing vortex formation and sustenance. The variation of interfacial momentum exchange with the increase in air flows and its impact on vortex frequencies can be explained from the finding of Liu et al. ${ }^{31)}$ who have investigated bubble size distribution in continuous casting by using both water and numerical models. According to their findings, the increase in gas flow rate would lead to arise in the mean diameter of the bubbles. Because of larger buoyancy, larger bubbles float up to the meniscus soon after their emergence from the SEN ports, ${ }^{32)}$ thus reducing the horizontal dispersion of the bubbles. Additionally, volume fraction near the SEN has been observed to increase with the increase in air flow rates.

Table 4. Interactive effect of air flow rate and water flow rate at SEN submergence depth $60 \mathrm{~mm}$.

\begin{tabular}{|c|c|c|c|c|c|c|c|c|c|}
\hline \multirow{4}{*}{$\begin{array}{c}\text { Air } \\
\text { Flow } \\
\text { Rate } \\
(1 / \mathrm{min})\end{array}$} & \multicolumn{9}{|c|}{ Vortex Frequency (\#/min) } \\
\hline & \multicolumn{3}{|c|}{ Clogging $0 \%$} & \multicolumn{3}{|c|}{ Clogging 33\% } & \multicolumn{3}{|c|}{ Clogging $66 \%$} \\
\hline & \multicolumn{3}{|c|}{$\begin{array}{c}\text { Water Flow Rate } \\
\qquad(1 / \mathrm{min})\end{array}$} & \multicolumn{3}{|c|}{$\begin{array}{c}\text { Water Flow Rate } \\
\qquad(1 / \mathrm{min})\end{array}$} & \multicolumn{3}{|c|}{$\begin{array}{c}\text { Water Flow Rate } \\
\qquad(1 / \mathrm{min})\end{array}$} \\
\hline & 38 & 45 & 50 & 38 & 45 & 50 & 38 & 45 & 50 \\
\hline 0 & 4.6 & 5.6 & 7.2 & 5.2 & 7 & 8.4 & 6.6 & 8.2 & 9.2 \\
\hline 1 & 0.2 & 2.4 & 3.8 & 1.2 & 3 & 4 & 1.8 & 3.4 & 4.2 \\
\hline 2 & 0.4 & 1 & 1.6 & 0.6 & 1.4 & 1.8 & 1.2 & 1.8 & 2 \\
\hline 3 & 0 & 0.8 & 1.4 & 0.6 & 0.8 & 0.8 & 1.2 & 1.6 & 0.4 \\
\hline
\end{tabular}


Thomas et al $^{33)}$ have reported that the terminal velocity of the bubbles increases with its size. In sum, higher air flow rates produce bubbles with larger diameter, terminal velocity and higher volume fraction near the SEN. Therefore, the retardation of the y-directed velocities during the interaction between ascending air bubbles and the liquid streams approaching the SEN would be high at higher air flow rates. As a consequence, the shearing effect and the resultant vortex formation and frequencies would be reduced.

On contrary to this phenomenon, increase in the water flow rate values has lead to an increase in vortex frequencies. This can be observed by examining any row of the data from Table 4. For instance, from 2 nd row of Table 4, i.e., at air flow rate $11 / \mathrm{min}$ and degree of clogging $33 \%$ (see 5 th to 7 th columns), the vortex frequencies are 1.2, 3 and 4 for the corresponding water flow rates 38, 45 and $50 \mathrm{l} / \mathrm{min}$ respectively. The reason is that the increase in water flow rates would increase the horizontal velocities of liquid flow streams at the meniscus. And hence, there would be more shearing between oppositely approaching flow streams near the SEN and thus more swirling flow and vortex formation.

\subsubsection{Interactive Effect of Air Flow Rate and SEN Sub- mergence Depth}

In the absence of air injection, SEN submergence depth has very limited effect on vortex frequency values. ${ }^{24)}$ This data is tabulated in 2nd to 4th columns of Table 5. For instance, data from the 4 th columnof Table 5 reveals that vortex frequencies at clogging $66 \%$ and water flow rate 50 1/min are 9.4, 9.2 and 9.4 for the corresponding SEN submergence depth values 40,60 and $80 \mathrm{~mm}$ respectively. With the injection of air, the observations are strikingly different. For a given air flow rate, increase in SEN submergence depth has reduced vortex frequencies. This data is presented in rest of the columns of Table 5. From all these columns, it is evident that the increase in SEN submergence depth from 40 to $80 \mathrm{~mm}$ has reduced vortex frequency values. For example, data from the 10th column shows that at air flow rate $21 / \mathrm{min}$ and clogging $66 \%$, the vortex frequency values are 3.8, 2.2 and 0.6 for the SEN submergence depth values 40, 60 and $80 \mathrm{~mm}$ respectively. With air injection, at deeper SEN submergence depth, the vortex frequencies are reduced to very low values in all clogging conditions. This is a very important observation. This means that for clog-prone grades, operating at relatively deeper SEN submergence depth would reduce vortex formation despite the degree of SEN port clogging. After validating this observation with the plant data, this can be suggested as an operational practice.
The reason for low vortex frequency values at deeper SEN submergence depth is due to the variation of the ascending air bubbles' flow pattern in the upper recirculation with the variation in submergence depth. At shallow submergence depth, the air bubbles traversing along the upper recirculation loop, hit the meniscus roughly at the middle of the SEN and narrow wall. On the contrary, at deeper submergence depth, gas bubbles travelling along the upper recirculation loop, reach a point which is very close to the SEN. Sometimes, the gas bubbles are found to traverse through the gap between the wide face and the SEN and reach the other side of the SEN. This variation in the flow patterns is clearly demonstrated in Fig. 4. In Figs. 4(a) and 4(d), white lines are drawn along the mean path of the bubble dispersion region as to highlight the variation in the upper circulation patterns. Comparison between the flow patterns as shown in the top and bottom rows of pictures of Fig. 4, it becomes evident that the flow loop at deeper SEN submergence depth is different from that observed at shallow submergence in all clogging conditions. At deeper submergence depth, a larger fraction of air bubbles strike the meniscus in the close vicinity of the SEN.

As known, the shearing effect and thus the vortex formation is relatively high in the close proximity of the SEN under normal conditions. At deeper SEN submergence, as observed in this experiment, the ascending gas bubbles would reach to the close proximity of the SEN and therefore, interact with the swirling flows formed by shearing effect. During this interaction, the exchange of the momentum would retard the angular velocities of the rotational flows. This would suppress the vortex formation/sustenance near the SEN. In some situations, owing to this reason, the point of vortex formation has been slightly moved away from the SEN (see Fig. 4(e)). Schematic representation of the variation in flow patterns is shown in Fig. 5.

As to quantify the flow asymmetry and to establish the connection between variation of mean flow velocities and the vortex frequencies, y-directed velocities (see Fig. 3) at the meniscus are measured and the mean values are depicted in Fig. 6. In this figure, the two plots at the top row display the average flow values at the locations $L_{150}$ and $R_{150}$ and the two plots in the bottom row show the variation at the positions $\mathrm{L}_{250}$ and $\mathrm{R}_{250}$ respectively. In each plot, variation of mean flow values against four different air flow rates measured at all the three SEN submergence depths is displayed (see legend). From Fig. 6(a), it is clear that the mean flow velocities measured at the three different SEN submergence depths and at air flow rate value $0 \mathrm{l} / \mathrm{min}$ are similar $(0.15$, 0.15 and $0.16 \mathrm{~m} / \mathrm{s})$. But, the increase in air flow rate has

Table 5. Interactive effect of air flow rate and SEN submergence depth at water flow rate $501 / \mathrm{min}$.

\begin{tabular}{|c|c|c|c|c|c|c|c|c|c|c|c|c|}
\hline \multirow{4}{*}{$\begin{array}{l}\text { SEN submergence } \\
\text { Depth }(\mathrm{mm})\end{array}$} & \multicolumn{12}{|c|}{ Vortex Frequency (\#/min) } \\
\hline & \multicolumn{3}{|c|}{ Air Flow Rate- 0 (1/min) } & \multicolumn{3}{|c|}{ Air Flow Rate- 1 (1/min) } & \multicolumn{3}{|c|}{ Air Flow Rate- 2 (1/min) } & \multicolumn{3}{|c|}{ Air Flow Rate- $3(1 / \mathrm{min})$} \\
\hline & \multicolumn{3}{|c|}{ Clogging } & \multicolumn{3}{|c|}{ Clogging } & \multicolumn{3}{|c|}{ Clogging } & \multicolumn{3}{|c|}{ Clogging } \\
\hline & $0 \%$ & $33 \%$ & $66 \%$ & $0 \%$ & $33 \%$ & $66 \%$ & $0 \%$ & $33 \%$ & $66 \%$ & $0 \%$ & $33 \%$ & $66 \%$ \\
\hline 40 & 7 & 8 & 9.4 & 4.4 & 6.2 & 6 & 2.6 & 3.2 & 3.8 & 1.4 & 2.8 & 3.2 \\
\hline 60 & 7.2 & 8.4 & 9.2 & 3.6 & 4.2 & 2.8 & 1.6 & 2 & 2.2 & 0.4 & 0.6 & 0.8 \\
\hline 80 & 6.8 & 8.2 & 9.4 & 2.8 & 3 & 1.8 & 0.4 & 0.4 & 0.6 & 0.2 & 0.2 & 0.2 \\
\hline
\end{tabular}



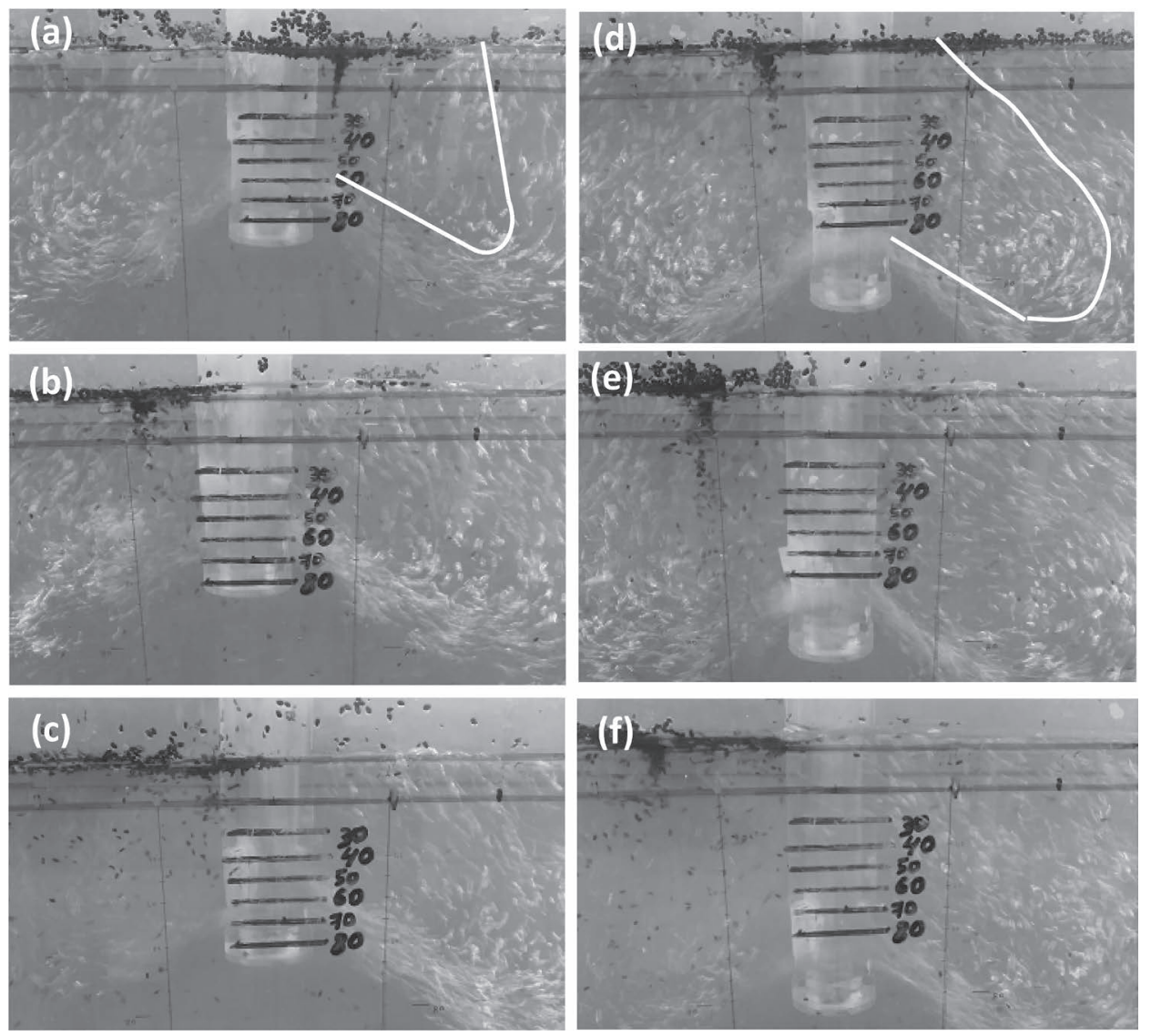

Fig. 4. Variation of flow patterns due to variation in SEN submergence depth (SD). Operating conditions, water flow rate $50 \mathrm{l} / \mathrm{min}$, air flow rate $1 \mathrm{l} / \mathrm{min}$. a) clogging 0 , SD $40 \mathrm{~mm}$ b) clogging 33\%, SD $40 \mathrm{~mm}$ c) clogging $66 \%$, SD 40 $\mathrm{mm}$ d) clogging 0 , SD $80 \mathrm{~mm}$ e) clogging 33\%, SD $80 \mathrm{~mm}$ f) clogging $66 \%$, SD $80 \mathrm{~mm}$.

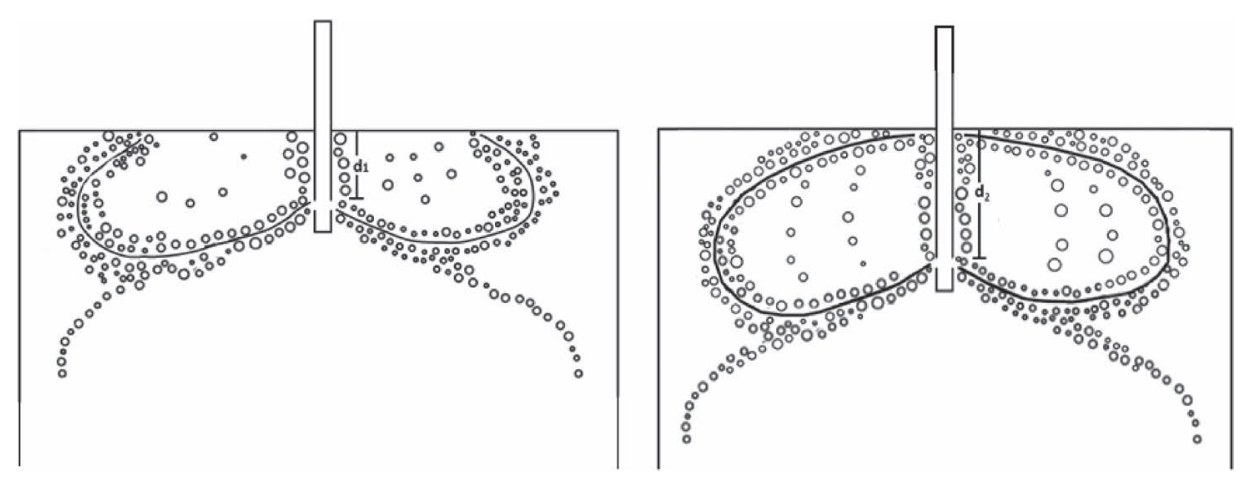

Fig. 5. Schematic representation of the variation in upper circulation flow pattern for shallow (d1) and deeper SEN submergence depth (d2).

induced variation. The mean flow velocities are found to decrease with the air flow rate. For instance, at the SEN submergence depth $80 \mathrm{~mm}$, the mean flow velocities at air flow rates $0,1,2$ and $31 / \mathrm{min}$ are $0.16,0.09,0.081$ and 0.07 respectively. Data measured at the location $\mathrm{R}_{150}$, as shown in Fig. 6(b), also followed the similar trend. Only difference is that the values at $R_{150}$ are higher than their counterparts measured at $\mathrm{L}_{150}$ and this is due the partial clogging of the left port (33\%). Mean velocities measured at the locations $\mathrm{L}_{250}$ and $\mathrm{R}_{250}$ are showed in Figs. 6(c) and 6(d). The behavior of the data is just similar to that of Figs. 6(a) and 6(b).

\subsubsection{Interactive Effect of Air Flow Rate and Clogging}

The effect of clogging on flow asymmetry and vortex frequency has been elaborately explained in the author's previous work. ${ }^{24)}$ In this section, the integrative effects of partial clogging and air flow rates are discussed. Figure7 graphically depicts variation of mean flow velocities at locations $\left(\mathrm{L}_{150}, \mathrm{R}_{150}\right),\left(\mathrm{L}_{250}, \mathrm{R}_{250}\right)$ and $\left(\mathrm{P}_{\mathrm{L}}, \mathrm{P}_{\mathrm{R}}\right)$. All nine plots, named as (a) to (i), showcase average velocities at SEN submergence depth $60 \mathrm{~mm}$, water flow rate $45 \mathrm{l} / \mathrm{min}$ and at the given partial clogging conditions. To elaborate, mean velocities at positions $\mathrm{L}_{150}$ and $\mathrm{R}_{150}$ at SEN submergence depth $40 \mathrm{~mm}$ are presented in plots Figs. 7(a), 7(b) and $7(\mathrm{c})$ having the left port clogging values $0 \%, 33 \%$ and $66 \%$ respectively. Similarly, the plots in the middle row, named as Figs. 7(d), 7(e) and 7(f), show data measured at positions $\left(\mathrm{L}_{250}, \mathrm{R}_{250}\right)$. And, plots in the last row, Figs. $7(\mathrm{~g})$, 7(h) and 7(i), depict data measured at positions $\left(\mathrm{P}_{\mathrm{L}}, \mathrm{P}_{\mathrm{R}}\right)$. Legends indicate the operating conditions. To provide the 
ISIJ International, Vol. 57 (2017), No. 9
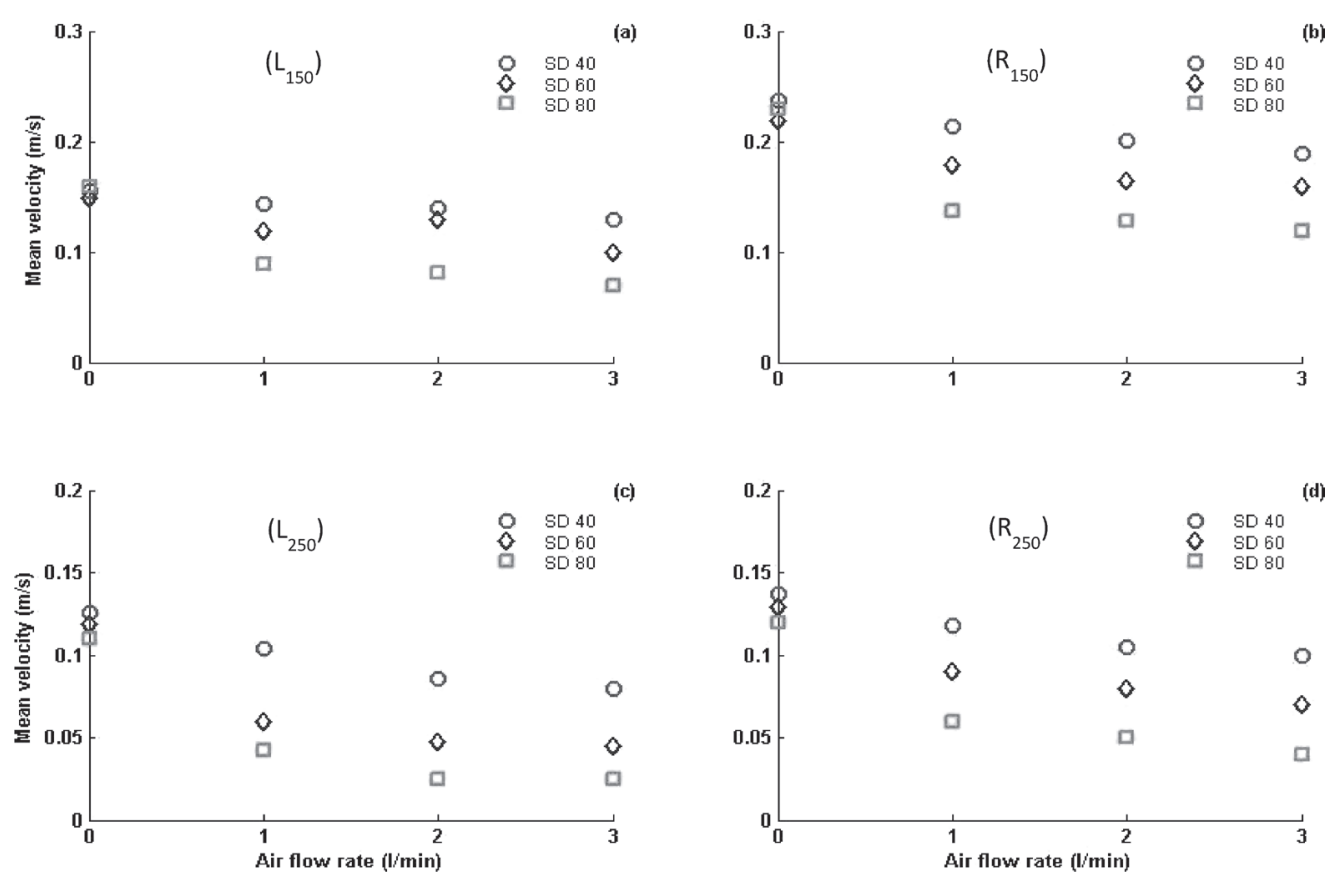

Fig. 6. Variation of average flow velocities at positions $\left(\mathrm{L}_{150}, \mathrm{R}_{150}\right),\left(\mathrm{L}_{250}, \mathrm{R}_{250}\right)$ and $\left(\mathrm{P}_{\mathrm{L}}, \mathrm{P}_{\mathrm{R}}\right)$ against water flow rates and at SEN depth $40 \mathrm{~mm}$.
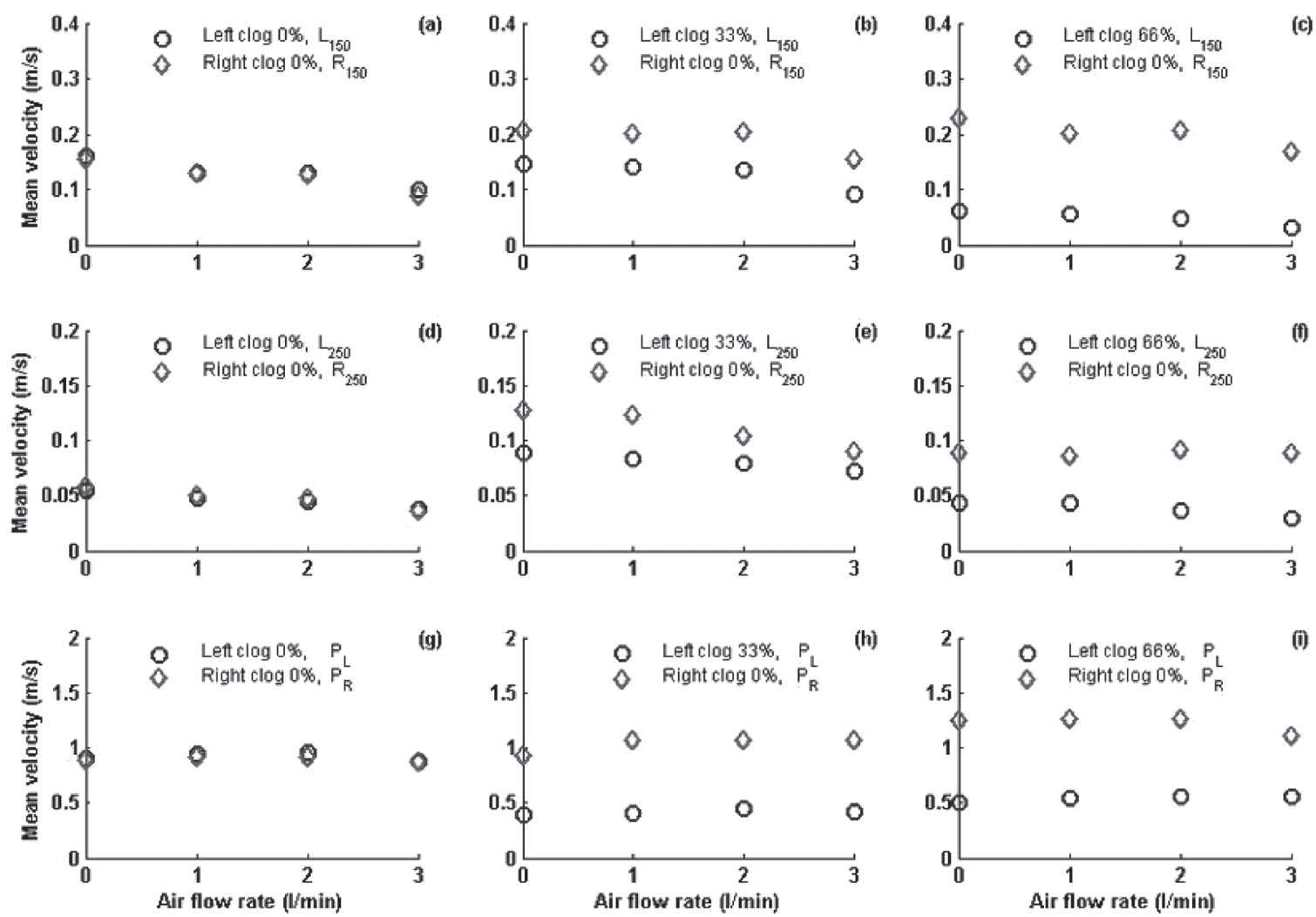

Fig. 7. Variation of average flow velocities at positions $\left(L_{150}, R_{150}\right),\left(L_{250}, R_{250}\right)$ and $\left(P_{L}, P_{R}\right)$ against degree of clogging and at SEN depth $60 \mathrm{~mm}$.

best representation of the data, $y$ axis scales are chosen differently for positions 150,250 and port exit and reader is requested to take a note of it. Observations from this graph are described below.

From Fig. 7(a), it is understood that the average velocities at $\mathrm{L}_{150}$ and $\mathrm{R}_{150}$ are very close to each other in the absence of partial clogging condition. However, these values are found to be decreasing with the rise in air flow rate. With the introduction of clogging, the velocities at $\mathrm{R}_{150}$ are higher than $\mathrm{L}_{150}$. Maximum difference was observed at the highest degree of clogging, i.e. $66 \%$. Even under clogging conditions, the effect of air flow rate is just the same as that was noticed in zero clogging conditions. In other words, average velocities are found to decrease with the increase in air flow rates. This can be understood from Figs. 7(b) and 7(c).

Similar conclusions can be derived from plots Figs. 7(d), 7(e) and 7(f). However, the observations from plot Fig. 7(g) are different in nature. In this plot, the port exit velocities 
Table 6. Interactive effect of air flow rate and clogging at SEN submergence depth $80 \mathrm{~mm}$ and water flow rate $45 \mathrm{l} / \mathrm{min}$.

\begin{tabular}{cccc}
\hline \multirow{2}{*}{$\begin{array}{c}\text { Air Flow Rate } \\
(1 / \text { min })\end{array}$} & \multicolumn{3}{c}{ Vortex Frequency (\#/min) } \\
\cline { 2 - 4 } & Clogging $0 \%$ & Clogging 33\% & Clogging 66\% \\
\hline 0 & 6 & 7.2 & 7.8 \\
1 & 1 & 1.4 & 1.8 \\
2 & 0.4 & 0.4 & 0.6 \\
3 & 0.2 & 0.2 & 0.2 \\
\hline
\end{tabular}

show a slightly rising trend followed by mild drop against the air flow rate values. For example, mean velocities at the left port exit are $0.091,1.03,1.08$ and $1.01 \mathrm{~m} / \mathrm{s}$ for the air flow rate values $0,1,2$ and $3 \mathrm{l} / \mathrm{min}$. At the right port exit, the corresponding values are $0.995,1.01,1.06$ and $1.03 \mathrm{~m} / \mathrm{s}$. The possible reason for the rise in the mean flow velocities at the port exit is the virtual mass force which accounts for relative acceleration and the drag force ${ }^{33)}$ between air and water. However, at very high value of air flow rate, i.e., $3 \mathrm{l} /$ min, this effect is found missing. The reason is that at high air flow rates, the increased turbulence would possibly have restricted further increase in water velocity. Similar behavior can be noticed from plots Figs. 7(h) and 7(i).

Vortex frequency variation as a function of clogging and air flow rate is presented in Table 6. The operating conditions are SEN submergence depth $80 \mathrm{~mm}$ and water flow rate $45 \mathrm{l} / \mathrm{min}$. From this table, it can be realized that the increase in degree of clogging has increased vortex frequencies, but the rise in air flow rate has a reduced vortex frequencies. This can be explained with the help of a data instance, mentioned in the second row from the table. At air flow rate $11 / \mathrm{min}$, the vortex frequencies are $1,1.4$ and 1.4 at clogging $0 \%, 33 \%$ and $66 \%$ respectively. At a higher value of air flow rate, i.e. $21 / \mathrm{min}$, the frequencies are 0.4 , 0.4 and 0.6 respectively.

\subsubsection{Salient Characteristics of Vortices}

At SEN submergence depth $40 \mathrm{~mm}$ and water flow rate $50 \mathrm{l} / \mathrm{min}$, vortices of minimum depth $50 \mathrm{~mm}$ are counted from video recordings. This data is summarized in Table 7. From this data, it is understood that number of vortices having a minimum depth $50 \mathrm{~mm}$ are found to decrease with the increase in air flow rates. Differing this, vortex number is found to increase with the rise in degree of clogging.

Another interesting observation captured in these experiments is shown in Fig. 8. In this figure, the entrained sesame seeds column exhibited a bend towards the port of the SEN and its end, interestingly, terminated in the port of the SEN. One possible reason for this behavior is the lower pressure zone near the SEN port which could have caused the bend in the vortex. This low pressure zone also leads to 'back-flow' at the SEN port. ${ }^{23)}$

\section{Conclusions}

Water model experiments have been carried out to investigate the interactive effects of the operating parameters, including, water flow rate, partial SEN submergence depth and air flow rate and the operating condition clogging of the
Table 7. Variation of vortex depth with air flow rates at SEN submergence depth $40 \mathrm{~mm}$ and water flow rate $50 \mathrm{l} / \mathrm{min}$.

\begin{tabular}{cccc}
\hline \multirow{2}{*}{$\begin{array}{c}\text { Air Flow Rate } \\
(1 / \mathrm{min})\end{array}$} & \multicolumn{3}{c}{$\begin{array}{c}\text { No of Vortices having depth }(>=50 \mathrm{~mm}) \\
\text { (from } 5\end{array}$} \\
\cline { 2 - 4 } & $\begin{array}{c}\text { Clogginute video duration) } \\
\text { Clo } \%\end{array}$ & $\begin{array}{c}\text { Clogging } 33 \% \\
\text { Clogging } 66 \%\end{array}$ \\
\hline 0 & 11 & 13 & 19 \\
1 & 9 & 10 & 11 \\
2 & 6 & 7 & 8 \\
3 & 1 & 4 & 5 \\
\hline
\end{tabular}
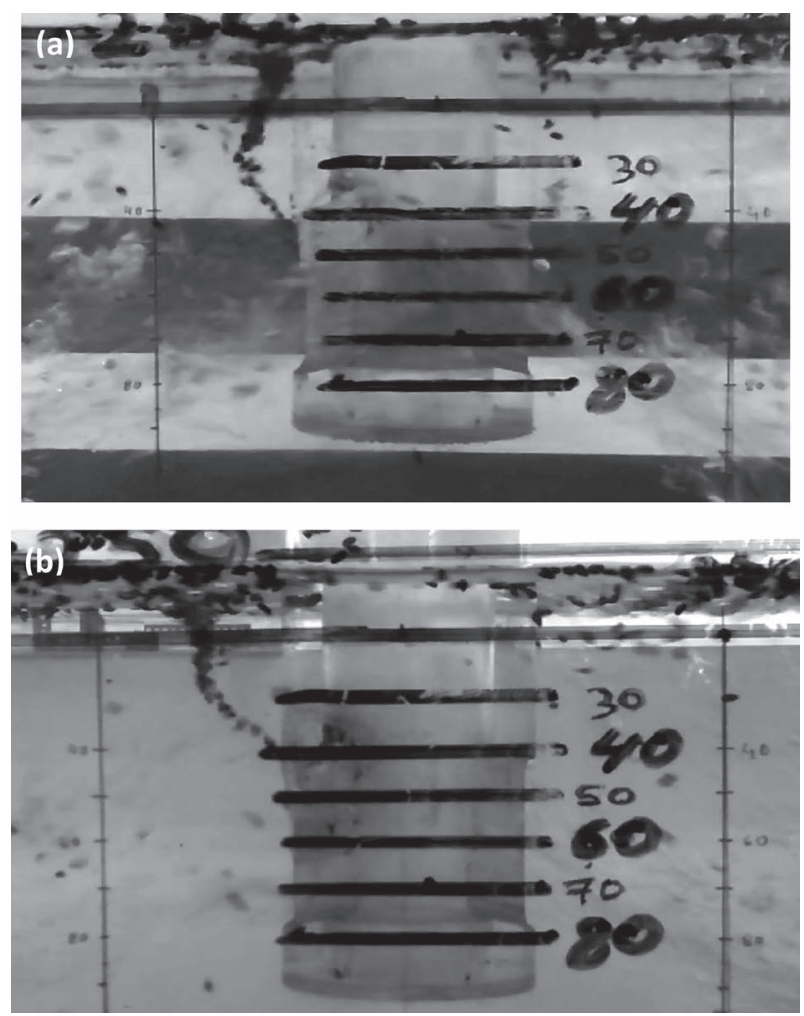

Fig. 8. Bend in the entrained sesame seeds column towards the partially clogged port. Operating conditions-water flow rate $50 \mathrm{l} / \mathrm{min}$, SEN submergence depth $40 \mathrm{~mm}$, air flow rate $1 \mathrm{l} / \mathrm{min}$. (a) clogging $33 \%$, (b) clogging $66 \%$.

SEN port. Similitude analysis was conducted to establish a link between flows in 0.4-scale water model and the actual slab caster with Argon-steel operational data. Sesame seeds were added as the tracer particles to observe particle entrainment due to vortexing. Video recording of vortex formation was done. Also, instantaneous velocity values at the submeniscus (20 mm below the meniscus) using impeller probe have been measured. This data has been used to analyze and quantify the vortex characteristics and flow asymmetry. The key findings of this research are summarized as follow:

(1) Operating parameters, water flow rate and degree of clogging have been found to increase vortex formation.

(2) Increase in air flow rates has reduced vortex frequency values. At higher air flow rate, the sizes of the bubbles those escape in the vicinity of SEN would increase. With the size, the terminal velocity values also increase. Additionally, increase in air flow rate increases the volume fraction of the air bubbles near the SEN. And hence, retarding effect of the y-directed velocity of the liquid streams at 
the meniscus would high. This would reduce shearing effect and thus vortex frequencies

(3) Increase in air flow rates not only decreases the number of vortices but also their depths. Number of vortices having depth greater than $50 \mathrm{~mm}$ are found to decrease with the increase in air flow rates.

(4) At deeper immersion depth of the SEN, the point of interaction between the air bubbles flowing along the upper circulation loop and the water flow streams at the meniscus has been observed to be at the close vicinity of the SEN compared the same at shallow submergence depth. This means that the interaction between the air bubbles and swirling flows near the SEN would decrease the angular momentum of the formative vortices and thus reducing their propagation.

(5) The most striking observation of this investigation is that at deeper SEN submergence depth, the vortex frequencies are found be very low. This observation is independent of degree of clogging. This means that for clog-prone grades, operating at relatively deeper submergence depth can reduce formation of vortices. Hence, this can be a recommended operational practice!

\section{Acknowledgements}

Authors take this opportunity to express their heartfelt thanks to Dr. S. K. Ajmani and Mr. Vikas Singh, R\&D division of Tata Steel for their guidance and valuable inputs. Also, special thanks to Ms. Priyanka Pandey, Ms. Saisree and Mr. Rishabh Singh for their assistance.

\section{List of Symbols}

$\mathrm{d}$ : Diameter of the hole at the bottom of the stopper rod, $m$

L: Left side of the mold

R: Right side of the mould

P: Port

$\mathrm{U}$ : Characteristic velocity of liquid, $\mathrm{m} / \mathrm{min}$

w: Mould width, $\mathrm{m}$

$\mathrm{x}$ : Mould thickness, $\mathrm{m}$

Y: Characteristic length, $\mathrm{m}$

Q: Volumetric flow rate, $\mathrm{m}^{3} / \mathrm{min}$

$\mathrm{g}$ : Acceleration due to gravity, $\mathrm{m} / \mathrm{s}^{2}$

$\mathrm{V}$ : Characteristic velocity of gas, $\mathrm{m} / \mathrm{min}$

Subscripts

W: Water model

A: Actual caster

\section{Superscript}

m: Modified

\section{Greek Letters}
$\lambda$ : Scale down factor
$\rho$ : Density $\left(\mathrm{kg} / \mathrm{m}^{3}\right)$

\section{Abbreviations}

CS: Casting Speed
Fr: Froude Number

SEN: Submerged Entry Nozzle

SD: Submergence depth of SEN

WFR: Water Flow Rate

\section{REFERENCES}

1) World Steel Assosiation: World Steel in Figures 2015, http://www. worldsteel.org, (accessed 2015-12-15).

2) J. Szekely and R. T. Yadoya: Metall. Trans., 3 (1972), 2673.

3) B. G. Thomas, L. J. Mika and F. M. Najjar: Metall. Mater. Trans. B, 21B (1990), 387.

4) B. G. Thomas: Making, Shaping and Treating of Steel, 11th ed., Casting Volume, ed. by A. Cramb, AIST Steel Foundation, Warrendale, PA, (2003), 14.1.

5) Y. H. Wang: 73rd Steelmaking Conf. Proc., ISS-AIME, Warrendale, PA, (1990), 473.

6) M. Iguchi, J. Yoshida, T. Shimizu and Y. Mizuno: ISIJ Int., 40 (2000), 685.

7) T. Watanabe and M. Iguchi: ISIJ Int., 49 (2009), No. 2, 182.

8) L. C. Hibbeler and B. G. Thomas: AISTech Proc., AIST, Warrendale, PA, (2013), 1215 .

9) Y. Miki and S. Takeuchi: ISIJ Int., 43 (2003), 1548.

10) L. Zhang, Y. Wang and X. Zuo: Metall. Mater. Trans. B, 39B (2008), 534.

11) R. Chaudhary, G. G. Lee, B. G. Thomas, S. M. Cho, S. H. Kim and O. D. Kwon: Metall. Mater. Trans. B, 42B (2011), 300.

12) Q. He: ISIJ Int., 33 (1993), 343.

13) M. Gebhard, Q. L. He and J. Herbertson: 76th Steelmaking Conf. Proc., ISS-AIME, Warrendale, PA, (1993), 441.

14) B. Li and F. Tsukihashi: ISIJ Int., 45 (2005), 30

15) H. Bai and B. G. Thomas: Metall. Mater. Trans. B, 32B (2001), 253.

16) Y. Miki, H. Kitaoka, T. Sakuraya and T. Fujii: ISIJ Int., 32 (1992), 142.

17) T. B. Braun, J. F. Elliott and M. C. Flemings: Metall. Trans. B, 10B (1979), 171.

18) L. Zhang and B. G. Thomas: Metall. Mater. Trans. B, 37B (2006), 733.

19) S. Rödl, H. Schuster, S. Ekerot, G. Xia, N. Veneri, F. Ferro, S. Baragiola, P. Rossi, S. Fera, V. Colla, G. Bioli, M. Krings, L. F. Sancho, A. Diaz, M. Andersson and N. Kojola: New Strategies for Clogging Prevention for Improved Productivity and Steel Quality, Final Report, European Commission, Luxembourg, (2012), 36.

20) J. Herbertson, Q. L. He, P. J. Flint and R. B. Mahapatra: 74th Steelmaking Conf., ISS, Warrendale, PA, (1991), 171.

21) N. Kasai and M. Iguchi: ISIJ Int., 47 (2007), 982.

22) K. Watanabe, K. Tsutsumi, M. Suzuki, M. Nakada and T. Shiomi: ISIJ Int., 49 (2009), 1161.

23) S. M. Cho, S. H. Kim, R. Chaudhary, B. G. Thomas, H. J. Shin, W. Y. Choi and S. K. Kim: Iron Steel Technol., 9 (2012), 85.

24) P. S. Srinivas, A. Singh, J. M. Korath and A. K. Jana: Ironmaking Steelmaking, (Published online 2016-08-05). DOI: 10.1080/ 03019233.2016.1215948.

25) V. Singh, S. K. Dash, J. S. Sunitha, S. K. Ajmani and A. K. Das: ISIJ Int., 46 (2006), 210.

26) A. Ramos-Banderas, R. D. Morales, R. Sánchez-Perez, L. Garcia-Demedices and G. Solorio-Diaz: Int. J. Multiph. Flow, 31 (2005), 643.

27) R. Sánchez-Perez, R. D. Morales, M. Diaz-cruz, O. Olivares-xometl and J. Palafoxramos: ISIJ Int., 43 (2003), 637.

28) Z. Liu, F. Qi, B. Li and M. Jiang: J. Iron Steel Res. Int., 21 (2014), 1081.

29) Z. Liu, B. Li and M. Jiang: Metall. Mater. Trans. B, 45B (2014), 675.

30) R. Chaudhary, B. T. Rietow and B. G. Thomas: Inclusions and Clean Steels, Materials Science and Technology Conf., AIST/TMS, Warrendale, PA, (2009), 1090.

31) Z. Liu, L. Li, F. Qi, B. Li, M. Jiang and F. Tsukihashi: Metall. Mater. Trans. B, 46B (2015), 406.

32) T. Zhang, Z. G. Luo, C. L. Liu, H. Zhou and Z. S. Zhou: Powder Technol., 273 (2015), 154

33) B. G. Thomas, A. Dennisov and H. Bai: Proc. 80th Steelmaking Conf., ISS, Warrendale, PA, (1997), 1. 